\title{
Pollen-based reconstructions of past land-cover change in Latin America
}

\author{
Sonia L. Fontana', T. Giesecke', P. Kuneš² and M.-J. Gaillard ${ }^{3}$
}

Salvador de Bahia, Brazil, 29-31 October 2016

\begin{abstract}
Latin America is an important region for the understanding of the global climate system as it extends from the northern hemisphere into the high southern latitudes. Few synoptic studies are available for this continental space. The purpose of this workshop was to bring together Latin American researchers working on past vegetation reconstruction to better integrate the local scientific community into the activities of the PAGES LandCover6k working group (Gaillard et al. 2015). Scientifically, a strong focus was to stimulate participants to attempt quantitative reconstructions and providing them with the tools to do so. The meeting attracted 22 scientists at all career stages, from Mexico, Colombia, Brazil, Bolivia, Argentina, Russia and Germany.
\end{abstract}

The workshop provided an overview of available methods for pollen-based reconstruction of land cover with emphasis on the Landscape Reconstruction Algorithm, including the REVEALS and LOVE models (Sugita 2007). Lectures also addressed the parameters required for these applications, including the need to estimate relative pollen productivity for selected plant taxa of interest, as well as the fall speed (settling velocity) of the respective pollen types. Validation and application of these models were illustrated through studies in Europe, North America and China. The modern analogue technique was discussed as an alternative way to obtain quantitative estimates of the cover of major vegetation units, such as woodland and open land, without the need of a detailed understanding of the pollenvegetation relationship. However, modern analogue techniques need a large number of surface sediment samples representing good modern analogues of past vegetation, which is problematic in Latin America due to very recent and drastic land-cover change. The training course followed the path from vegetation surveys and estimating relative pollen productivities to their application in REVEALS-based reconstructions of past plant cover.

Discussions focused on the application of these approaches to the diverse ecosystems of Latin America that have their unique challenges for pollen-based quantitative vegetation reconstructions. Estimating the taxon-specific production and dispersal of pollen is crucial for a better understanding of the results portrayed in pollen diagrams and builds the basis for quantitative reconstructions. This type of investigation is scarce in Latin America and a challenging

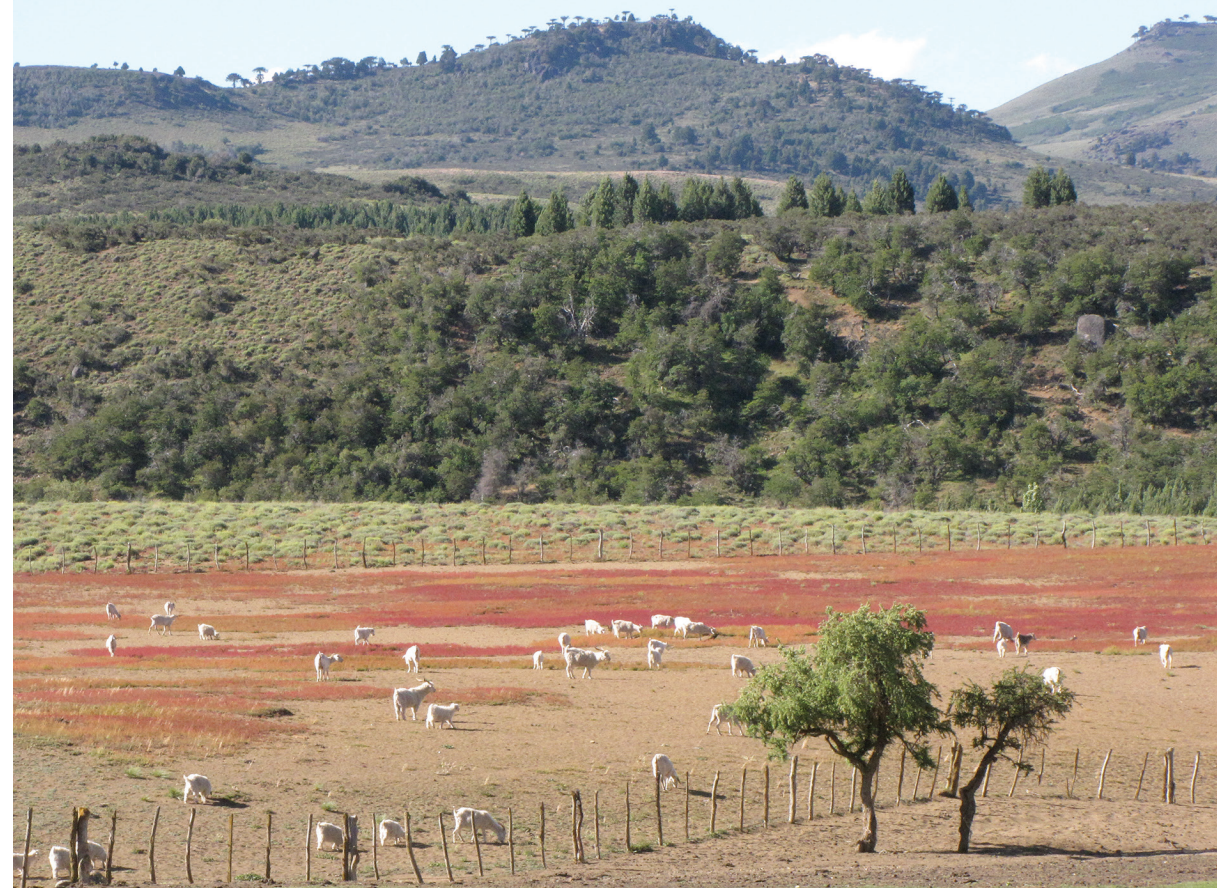

Figure 1: Human land use at the forest-steppe ecotone in northern Patagonia. Rumex acetossella (red color in the grazed land) commonly known as sheep's sorrel or red sorrel, is a major anthropogenic indicator of animalbased disturbance activities occurring during the last few hundred years.

task, in particular in tropical and subtropical environments with high plant diversity. First attempts aiming to estimate pollen productivity and dispersal in southwest Amazonia and at the forest-steppe ecotone in Patagonia were presented and discussed.

While LandCover6k aims to quantify human-induced changes in land cover, Latin America contains different environments where the proportion of woodland versus grassland has changed during the Holocene due to shifts in precipitation and temperature, namely the upper mountain forest versus páramo vegetation in the Andes mountains, the forest grasslands in the Llanos Orientales, the Mata Atlântica in Brazil, and the forest-steppe ecotone in Patagonia. However, these ecosystems were also preferred by humans that controlled the encroachment of forest with fire. Therefore, the effects of human action and climate change are often difficult to disentangle (Fig. 1).

Databases are an important prerequisite for larger synoptic studies. The Latin American Pollen Database and new tools available through the Neotoma Database were presented and discussed. Plans were made to develop a modern surface-sample pollen dataset and set up projects which aim to achieve pollen-based reconstructions of plant cover in the past.

This workshop was organized in collaboration with the XIV International Palynological Congress, the Federal University of Bahia and local colleagues, Francisco Hilder Magalhães e Silva, Paulino Pereira Oliveira, Vivian Jeske-Pieruschka, Kelly Regina Batista Leite, and Lázaro Benedito da Silva.

Further details about LandCover6k and this workshop can be found at www.pastglobalchanges.org/ini/wg/landcover6k/intro

\section{AFFILIATIONS}

'Department of Palynology and Climate Dynamics, University of Göttingen, Germany

2Department of Botany, Charles University, Prague, Czech Republic

${ }^{3}$ Biology and Environmental Science, Linnaeus University, Kalmar, Sweden

\section{CONTACT}

Sonia Fontana: Sonia.Fontana@biologie.uni-goettingen.de REFERENCES

Gaillard MJ et al. (2015) PAGES Mag 23: 38-39

Sugita S (2007) Holocene 17: 229-257 